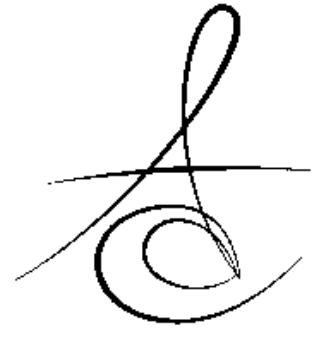

Makale Kodu/Article code: 1163

Makale Gönderilme tarihi: 04.05 .2013

Kabul Tarihi: 30.10.2013

\section{FARKLI ADEZİV SİMANLAR İLE SİMANTE EDİLEN FARKLI FİBER POSTLARIN MİKROSIZINTILARININ KANTİTATİF OLARAK DEĞERLENDİRİLMESİ}

\section{QUANTITATIVE MICROLEAKAGE EVALUATION OF DIFFERENT FIBER POSTS CEMENTED WITH DIFFERENT ADHESIVE CEMENTS}

\author{
Doç. Dr.Uğur ERDEMİR* \\ Dr.Sevda ÖZEL ${ }^{* *}$
}

\author{
Doç. Dr.Hande Şar SANCAKLI* \\ Prof. Dr.Esra YILDIZ
}

\section{ÖZET}

Amaç: $\mathrm{Bu}$ in vitro çalışmanın amacı güncel adeziv yaklaşımla simante edilen fiber post sistemlerin dişin üç ayrı bölgesindeki mikrosızıntılarının karşılaştırımasıdır.

Gereç ve yöntem: 42 adet düz kök yapısına sahip üst santral ve kanin dişler step-back tekniği ile genişletilip lateral kondensasyon ile güta-perka kullanılarak dolduruldu. Standard post preparasyonlarını takiben hazırlanan kökler iki farklı fiber post gruplarında kullanılmak üzere ayrıldı ve her bir adeziv siman grubu için (Panavia F 2.0, RelyX Unicem, Maxcem) 7 örnek olacak şekilde üç alt gruba ayrıldı. Örnekler 2500 kez (5$55 \mathrm{C})$ termal siklus işleminden geçirildi sonrasında 24 saat metilen mavisi solüsyonunda saklandı. Simante edilen örneklerden yatay olarak 3 er kesit elde edildi (Sevikal, Orta, Apikal) ve her bir kesit stereo mikroskop altında X12 büyütmede incelendi. Mikrosızıntı, boyanan dentin yüzeylerinin tüm dentin yüzeyine oranlanması ile elde edildi. Veriler Kruskal-Wallis ve Mann-Whitney $U$ testleri kullanılarak istatistiksel olarak 0.05 anlamlılık düzeyinde değerlendirildi.

Bulgular: Karbon fiber postlar, cam fiber postlara göre servikal kök kesitlerinde istatistiksel olarak anlaml derecede daha yüksek mikrosızıntı göstermiştir $(p<0.05)$. Cam fiber post gruplarında ise en az sızıntı tüm kök kesitlerinde Panavia F 2.0 grubunda gözlenirken, en yüksek mikrosızıntı Maxcem gruplarında gözlenmiştir $(p<0.05)$. Post tiplerine bakılmaksızın, Panavia F 2.0 en az mikrosızıntı değerleri gösterirken, Maxcem tüm kök kesitlerinde en fazla mikrosızıntı değerlerine ulaşmıştır. Sonuç: Tüm kök kesitlerinde Panavia F 2.0 ile simante edilen cam fiber postlar en az mikrosızıntıyı göstermiştir. Anahtar kelimeler: Fiber post, mikrosızıntı, yapıtırma simanları.

\section{ABSTRACT}

Purpose: The aim of this in vitro study was to compare the microleakage of two fiber-reinforced post systems cemented with luting agents that utilize two currently available adhesive approaches in three segments of teeth.

Materials and Methods: Forty two extracted human maxillary central incisor and canine teeth with straight root canals were prepared using a step-back technique and obturated with gutta-percha using lateral condensation. Following standardized post-space preparations, the roots were divided into 2 fiber-post groups (Carbopost, RelyX Fiber Post) and further divided into 3 subgroups of 7 specimens each for the adhesive approach (Panavia F, RelyX Unicem, Maxcem). All specimens were thermal cycled 2500 times between $5^{\circ} \mathrm{C}$ and $55^{\circ} \mathrm{C}$ and stored in methylene-blue solution for 24 hours. Bonded specimens were cut horizontally into three sections (Cervical, Medium, Apical) and each section was evaluated using a stereomicroscope at original magnification X12. For each image, dye penetration was estimated as the ratio of methylene-blue-infiltrated surface divided by total dentin surface. The data were statistically analyzed by using the Kruskal-Wallis test and Mann-Whithney U test $(p<0.05)$.

Results: Carbon fiber-reinforced posts demonstrated significantly higher microleakage in cervical root sections $(p<0.05)$ than the glass fiber-reinforced posts. For the glass fiber-reinforced post groups, the least microleakage was observed for the Panavia F 2.0 in all root sections, while the highest microleakage was observed for the Maxcem $(p<0.05)$. Regardless of the post types, Panavia F 2.0 demonstrated the highest sealing ability, while Maxcem exhibited higher microleakage in all root sections $(\mathrm{p}<0.05)$.

Conclusion: In all root section glass fiber-reinforced posts cemented with Panavia $F 2.0$ had the least microleakage when assessed using a dye penetration technique.

Keywords: Fiber post, microleakage, adhesive cements

\footnotetext{
*istanbul Üniversitesi Dişhekimliği Fakültesi Diş Hastalıkları ve Tedavisi AD,

** İstanbul Üniversitesi Tıp Fakültesi Bioistatistik ve Tıp Bilişimi AD,

"Bu çalışma, 31 Ağustos - 3 Ey/ül 2011'de, "45. CED-IADR, Budapeşte/Macaristan" toplantısında poster olarak sunulmuştur.
} 
Atatürk Üniv. Diş Hek. Fak. Derg.

J Dent Fac Atatürk Uni

Cilt:24, Sayı:1, Yıl: 2014, Sayfa: 50-57
ERDEMİR, SANCAKLI, ÖZEL, YILDIZ

\section{Gíriş}

Aşırı kuron harabiyeti gösteren endodontik tedavi görmüş dişlerin restorasyonunda post ve kor uygulamaları sıklıkla kullanılmaktadır., ${ }^{1,2} \mathrm{Bu}$ amaçla kullanılan metal pre-fabrik post sistemlerinin yetersiz retansiyona ve çeşitli kök kırıklarına neden olabileceklerinin yanı sıra korozyon ve alerjik reaksiyon gibi dezavantajlara da sahip olabilecekleri yapılan çalışmalarda bildirilmiştir. ${ }^{3,4}$ Son yıllarda adeziv sistemlerde yaşanan gelişmeler ve artan estetik post-kor uygulamaları, korozyona dirençli, alerjik reaksiyon göstermeyen, metal postlara göre daha estetik ve tekrar uygulanabilirliği daha kolay olan pre-fabrik fiber ile güçlendirilmiş polimer post sistemlerinin yaygın olarak kullanılmasını sağlamıştır.5,6 Fiber ile güçlendirilmiş kompozit (FGK) post sistemleri ilk olarak 1990'larda aşırı harabiyet gösteren endodontik tedavili dişlerin restorasyonunda metal post-kor sistemlere alternatif olarak üretilmişlerdir. ${ }^{7}$ FGK postlar, reçine bir matriks içerisinde silan bağlama ajanlarıyla matrikse bağlanmış karbon, kuartz, zirkonyum veya cam fiberlerden oluşan post sitemleridir. ${ }^{8}$ Pek çok çalışmada FGK post sistemlerinin en büyük avantajının elastik modülüsünün dentine benzer olduğu ve bu post sistemlerinin oklüzal stresleri kök dentini boyunca dağıtarak daha az kök kırıklarına neden olduğu bildirilmiştir.6,9-11

Fiber postların kök kanalına simantasyonunda ışık ile polimerize olan adeziv simanlar, ışık ileten fiber postlar ile birlikte kullanılsa dahi özellikle apikal bölgede adeziv simanın yetersiz polimerizasyonu nedeniyle önerilmemektedir. ${ }^{12} \mathrm{Bu}$ nedenle, genellikle geleneksel total-etching veya self-etching adeziv ile birlikte kullanılan dual-cure reçine simanlar veya son zamanlarda kullanıma giren asit, bağlayıcı ajan ve simanın bir arada olduğu self-adeziv dual-cure reçine simanlar fiber postların simantasyonunda yaygın olarak kullanılmaktadır. 2,4,6,8,13 Total-etching adeziv sistemlerde optimal bağlantının sağlanması için ıslakbağlanma (wet-bonding) tekniğinin uygulanması gereklidir, ${ }^{14}$ ancak derin ve dar kanal boşluğu içerisinde dentin yüzeyinin ıslaklığını kontrol etmenin zor olması bu uygulama prosedürünü kısıtlamaktadır. Selfetching adeziv uygulama prosedürü ise fosforik asit uygulama ve yıkama gibi prosedürlerin olmaması nedeniyle optimal bağlanmanın sağlanması için daha az teknik hassasiyet gerektiren bir uygulama yöntemidir. ${ }^{15}$ Self-adeziv reçine bazlı simanlar ise dentin yüzeyinde her hangi bir hazırlık işlemi gerektirmeyen, azalmış uygulama prosedürü ile teknik hassasiyeti daha az olan ve uygulayıcıya basit ve standart bir uygulama prosedürü sonrasında fiber postların simantasyonunu sağlayan sistemlerdir. ${ }^{16}$

Postların mekanik özellikleri, post-siman ara yüzey bağlanma dayanımı ve çeşitli post tipleri ile restore edilen dişlerin kırılma dirençleri ile ilgili birçok çalışma yapıımıştır. 2,4,8,17,18 Mikrosızıntı, ikincil çürüklerin başlaması ve hatta enfeksiyonların tekrarlamasına neden olarak post-kor restorasyonların uzun dönem başarısını etkilemesi nedeniyle önemli bir faktördür. ${ }^{19,20}$ Post uygulamalarında oluşan mikrosızıntının, post sisteminin sertliği, simanın çözünürlüğü ve post ile diş dokusu arasındaki adeziv bağlanma derecesiyle ilgili olduğu bildirilmiştir. ${ }^{19-21}$ Klinik uygulama bakımından adeziv siman-dentin arası bağlanmanın optimal olması önemlidir. Bu bağlantının bozulması veya yetersizliği, kuronal sızıntının oluşmasına neden olarak kuronal diş dokularında oluşan mikromekanik bağlantının da bozulmasına neden olacaktır. ${ }^{22}$

Kuronal ve apikal mikrosızıntı çalışmalarında genellikle bakteri, boya ve izotopların penetrasyonu, ${ }^{23}$ konfokal mikroskop ${ }^{24}$ ve sıvı filtrasyon yöntemi ${ }^{21}$ gibi değişik test metodları kullanılmıştır. Literatürler incelendiğinde, kullanımı gün geçtikçe artmakta olan self-adeziv reçine simanlar ile simante edilen farklı tipteki FGK postların boya penetrasyonu sonrasında mikrosızıntı ölçümünü görüntüleme analizörü kullanarak boyanan dentin yüzeylerinin tüm dentin yüzeylerine oranlanması ile kantitatif olarak inceleyen çalışmalar kısıtııdır. ${ }^{20,25}$.

Bu nedenle bu in vitro çalışmanın amacı, güncel self-etching ve self-adeziv dual-cure adeziv siman sistemleri ile simante edilen farklı fiber post tiplerinin (cam fiber post; karbon fiber post) dişin üç ayrı bölgesindeki (kuronal, orta, apikal) mikrosızıntılarının kantitatif olarak karşılaştırılmasıdır. Çalışmanın hipotezi; kullanılan farklı yapıdaki yapıştıı simanlar ile simante edilen farklı post tiplerinin mikrosızıntısının benzer olacağı yönündedir.

\section{GEREÇ ve YÖNTEM}

42 adet düz köklü, periodontal nedenlerden ötürü çekilmiş, herhangi bir kırık veya endodontik tedavisi, post-kor restorasyonu bulunmayan üst çene santral $(n=23)$ ve kanin $(n=19)$ dişler çalışmada 
kullanıldı. Dişler üzerinde bulunan yumuşak doku artıkları ve diş taşları bir scaler yardımıyla uzaklaştırıldıktan sonra dişler kullanılıncaya kadar \%0.5 kloraminT çözeltisinde $4^{\circ} \mathrm{C}$ de en fazla 6 ay süre ile saklandı.

\section{Örneklerin hazırlanması}

Her bir dişin kuronal kısmı mine-sement sınırı altından kök kanal uzunluğu 14 mm olacak şekilde bir cetvel ile ölçülerek standardize edildikten sonra düşük devirli elmas disk (Isomet 1000, Buehler, Lake Bluff, $\mathrm{IL}, \mathrm{ABD}$ ) ile su soğutması altında kesilerek uzaklaştırıldı ve dişler endodontik tedavi için hazırlandı. Kök kanalı çalışma uzunluğu apikal foramenin $1 \mathrm{~mm}$ gerisinde olacak şekilde \#35 numara master apikal file (Maillefer, Ballaigues, İsviçre) kullanılarak aynı operatör tarafından hazırlandı. Kök kanalları K-file kanal eğeleri (Union Broach, New York, NY, ABD) ve \#2-4 numara Gates Glidden frezleri (Union Broach) kullanılarak ve her eğe ve frez kullanımından sonra $\% 5,25$ sodyum hipoklorit yıkama solüsyonu ile yıkanarak Step-back tekniği ile hazırlandı. Bu şekilde hazırlanan kök kanalları daha sonra distile su ile yıkandı ve kağıt koniler (Paper-points; DentsplyMaillefer) ile kurulanarak kanal dolgu patı (AH-Plus; Dentsply DeTrey GmbH, Konstanz, Almanya) ve güttaperka konları (Dentsply-Maillefer) ile lateral kondensasyon yöntemi ile dolduruldu. Kanal tedavilerin tamamlanmasını takiben kanal dolgu patının sertleşmesi için dişlerin kuronal kanal ağızları geçici bir restorasyon materyali (Cavit-G; 3M ESPE AG, Seefeld, Almanya) ile kapatılarak ışık geçirmeyen nemli bir kap içerisinde $37^{\circ} \mathrm{C}^{\prime}$ de 7 gün süreyle saklandı. ${ }^{21}$

\section{Post sistem/erin simantasyonu}

Kök kanalları postların yerleştirilmesinden önce apikal bölgede $4 \mathrm{~mm}$ gütta-perka kalacak şekilde mine-sement sınırından apikal yöne doğru $10 \mathrm{~mm}$ derinliğinde hazırlandı. Kuronal bölgede bulunan güttaperka peeso reamer (Dentsply-Maillefer) ile uzaklaştırıldıktan sonra kök kanalları $10 \mathrm{~mm}$ standart derinliğe kadar her bir post sisteminde bulunan özel kanal hazırlama drilleri ile hazırlandı (Tablo 1). Kanalların post uygulaması için hazırlanmasını takiben her bir kanal distile su ile yıkandı ve kanal kağıt koniler (Dentsply-Maillefer) ile kurulandı. Bu şekilde hazırlanan kök kanalları rastgele olarak 2 FGK post grubuna (cam fiber post, RelyX Fiber Post, 3M ESPE, Seefeld, Almanya; karbon fiber post, Carbopost, Carbotech, Ganges, Fransa) ve daha sonra da self-etching (Panavia F 2.0, Kuraray, Tokyo, Japonya) ve self- adeziv (RelyX Unicem, 3M ESPE, Seefeld, Almanya; Maxcem, Kerr Corporation, Orange, CA) olmak üzere 3 farklı adeziv yapıştırıcı siman grubuna ayrıldı $(n=7)$ (Tablo 1). Çalışmada her iki post tipinden de 1,6 mm çapında olanlar kullanıldı. Seçilen postlara uygun olarak kök kanalları fiber post sistemlerin setinde bulunan kanal hazırlama drilleri ile post çapına uygun kırmızı bantlı 1,6 mm çaplı post yuvası hazırlama drilleri ile hazırlanarak standardize edildi. Daha sonra postlar apikal uçtan itibaren hazırlanan kanal uzunluğu (10 mm) ve kor yapımı (4 mm) için kuronal kısmından $14 \mathrm{~mm}$ olacak şekilde işaretlenerek yatay yönde elmas fissür bir frez (Komet-Brasseler GmbH, Lemgo, Almanya) ile kesilerek kısaltıldı. Kullanılan post tipleri bu şekilde kısaltıldıktan sonra simantasyon işlemi öncesi yüzeyleri alkol ile temizlendi, distile su ile yıkandı ve hava ile kurutuldu.

Tablo 1. Çalışmada kullanılan materyaller ve özellikleri

\begin{tabular}{|c|c|c|c|c|}
\hline Materyal & $\begin{array}{l}\text { Adeziv } \\
\text { sistem }\end{array}$ & $\begin{array}{l}\text { Malzeme } \\
\text { tanımı }\end{array}$ & $\begin{array}{l}\text { Üretici } \\
\text { firma }\end{array}$ & $\begin{array}{l}\text { Üretim } \\
\text { no }\end{array}$ \\
\hline $\begin{array}{l}\text { Panavia F } \\
2.0\end{array}$ & $\begin{array}{l}\text { ED Primer } \\
\text { II }\end{array}$ & $\begin{array}{l}\text { Self-etch } \\
\text { adezivli } \\
\text { dual-cure } \\
\text { yapıştırıcı } \\
\text { siman }\end{array}$ & $\begin{array}{l}\text { Kuraray } \\
\text { Medical } \\
\text { Inc., Osaka, } \\
\text { Japonya }\end{array}$ & 41226 \\
\hline $\begin{array}{l}\text { RelyX } \\
\text { Unicem }\end{array}$ & -- & $\begin{array}{l}\text { Self-adeziv } \\
\text { dual-cure } \\
\text { yapıştırıcı } \\
\text { siman }\end{array}$ & $\begin{array}{l}\text { 3M ESPE, } \\
\text { Seefeld, } \\
\text { Almanya }\end{array}$ & 332878 \\
\hline Maxcem & -- & $\begin{array}{l}\text { Self-adeziv } \\
\text { dual-cure } \\
\text { yapıştırıcı } \\
\text { siman }\end{array}$ & $\begin{array}{l}\text { Kerr } \\
\text { Corporation, } \\
\text { Orange, CA }\end{array}$ & 2763026 \\
\hline Carbopost & -- & $\begin{array}{l}\text { Karbon fiber } \\
\text { post }\end{array}$ & $\begin{array}{l}\text { Carbotech, } \\
\text { Ganges, } \\
\text { Fransa }\end{array}$ & $\mathrm{CH} 112$ \\
\hline $\begin{array}{l}\text { RelyX } \\
\text { Fiber Post }\end{array}$ & -- & $\begin{array}{l}\text { Cam fiber } \\
\text { post }\end{array}$ & $\begin{array}{l}\text { 3M ESPE, } \\
\text { Seefeld, } \\
\text { Almanya }\end{array}$ & 035100608 \\
\hline $\begin{array}{l}\text { Filtek } \\
\text { Supreme }\end{array}$ & $\begin{array}{l}\text { Adper } \\
\text { Single } \\
\text { Bond } 2 \\
\end{array}$ & $\begin{array}{l}\text { Nanofil } \\
\text { kompozit }\end{array}$ & $\begin{array}{l}3 \text { M ESPE, St } \\
\text { Paul, MN, } \\
\text { ABD }\end{array}$ & $6 B Y$ \\
\hline
\end{tabular}

\section{Self-etching adeziv ile kombine yapıştırıcı} siman grubu

Panavia F 2.0 (Kuraray) yapıştırıcı simanın kullanıldığı bu grupta hem cam fiber post (RelyX Fiber Post) hem de karbon fiber postların (Carbopost) yüzeyleri simantasyon işlemi öncesi alkol ile temizlendi ve hava ile kurutuldu. Siman sistemin adezivi ED Primer II, üretici firma direktifleri doğrultusunda 1:1 oranında karıştırılarak kök kanalı dentinine uygulama fırçaları ile (Microbrush X, Microbrush Corp, Grafton, WI, USA) $30 \mathrm{~s}$ uygulandı, hafifçe hava ile kurutuldu ve kanal içinde kalan fazla adeziv kağıt koniler (Dentsply-

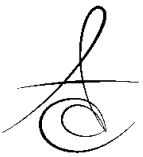


Maillefer) ile uzaklaştırıldı. Panavia F 2.0 A ve B patından eşit miktarda 20 s karıştırılarak elde edilen homojen siman patı bir lentülo (Dentsply-Maillefer) ile kanal boşluğuna uygulandı. Siman, post yüzeylerine de uygulandı ve uygulama sonrasında postlar yavaşça kanal içine yerleştirildi. Taşan siman artıkları fırça yardımıyla uzaklaştırıldıktan sonra kök yüzeyleri post yüzeyine dik olacak şekilde oklüzal yönden 600 $\mathrm{mW} / \mathrm{cm} 2$ ışık gücündeki halojen ışık cihazı (VIP; Bisco Inc. Schaumburg, IL, ABD) ile $40 \mathrm{~s}$ polimerize edildi. Her uygulama öncesi ışık gücü bir radyometre (Hilux Curing Light Meter, Benlioğlu Dental, Ankara, Türkiye) ile kontrol edilerek ışık yoğunluğunun uygunluğu test edildi.

\section{Self-adeziv siman grupları}

RelyX Unicem (3M ESPE) ve Maxcem (Kerr) self-adeziv yapıştırıcı simanların kullanıldığı bu gruplarda hem cam fiber post (RelyX Fiber Post) hem de karbon fiber postların (Carbopost) yüzeyleri simantasyon işlemi öncesi alkol ile temizlendi ve hava ile kurutuldu. RelyX Unicem (3M ESPE) grubunda, kapsülün karıştırılmasından sonra hazır hale gelen siman, kapsüle bağı değiştirilebilir özel uygulama ucu yardımıyla kanal boşluğuna ve post yüzeylerine uygulandı ve postlar yavaşça kanal içine yerleştirildi. Taşan siman artıkları fırça yardımıyla uzaklaştırıldıktan sonra, üretici firma direktifleri doğrultusunda simanın otopolimerizasyonu için $5 \mathrm{dk}$ beklendi. Daha sonra kök yüzeyleri yukarıda belirtildiği şekilde halojen ışık cihazı ile polimerize edildi.

Otokarıştırıcı sistemi olan Maxcem (Kerr) selfadeziv siman grubunda ise, adeziv siman karıştırıcının ucuna eklenen değiştirilebilir özel uygulama ucu yardımıyla kanal boşluğuna ve post yüzeylerine uygulandı ve postlar yavaşça kanal içine yerleştirildi. Taşan siman artıkları fırça yardımıyla uzaklaştırıldıktan sonra kök yüzeyleri yukarıda belirtildiği şekilde halojen ışık cihazı ile polimerize edildi.

$\mathrm{Bu}$ şekilde postların simantasyon işlemleri tamamlandıktan sonra nano dolduruculu bir kompozit materyali (Filtek Supreme; 3M ESPE, St Paul, MN, $A B D$ ) ile kuronal korları yapıldı. Bu amaçla kuronal dentin yüzeyleri \%37'lik fosforik asit (Scotchbond etchant, 3M ESPE) ile $15 \mathrm{~s}$ asitlendi, hava-su spreyi ile yıkandı ve kurulandı, daha sonra iki kat total-etch adeziv sistem (Adper Single Bond 2; 3M ESPE) uygulama fırçası yardımıyla uygulanarak 20 sn süre ile polimerize edildi. Nano doldurucu kompozit materyali her tabakası $1,5 \mathrm{~mm}$ yüksekliğinde olmak üzere 3 tabaka halinde $4,5 \mathrm{~mm}$ yüksekliğinde uygulandı ve her tabaka 20 s süre ile polimerize edildi. Bütün siman gruplarında kor yapımı aynı şekilde yapıldı. Bu şekilde hazırlanan dişler distile su içerisinde $37{ }^{\circ} \mathrm{C}^{\prime}$ de 24 saat saklandıktan sonra $30 \mathrm{~s}$ bekleme süresinde $5^{\circ} \mathrm{C}-55^{\circ} \mathrm{C}$ arasında 2500 kez Isısal dönüşüm işlemine tabi tutuldu. Isısal dönüşüm işlemi bittikten sonra dişler hava ile kurutuldu, boya penetrasyonunun önlenmesi için kök ucu pembe mum ile tıkandı ve dişler, kompozit kor restorasyonların $1 \mathrm{~mm}$ altından tüm kök yüzeylerini içine alacak şekilde 2 kat tırnak cilası ile boyandı. Daha sonra dişler \%2'lik metilen mavisinde (Merck, Darmstadt, Almanya) 24 saat bekletildi. Boya penetrasyonunun değerlendirilmesi için kök yüzeyleri kuronal kısmın 0,5 mm apikalinden her biri $3 \mathrm{~mm}$ kalınlığında 3 eşit kesit (kuronal, orta, apikal) olarak su soğutması altında elmas disk (Isomet 1000, Buehler, Lake Bluff, IL, ABD) ile kesildi (Şekil 1).

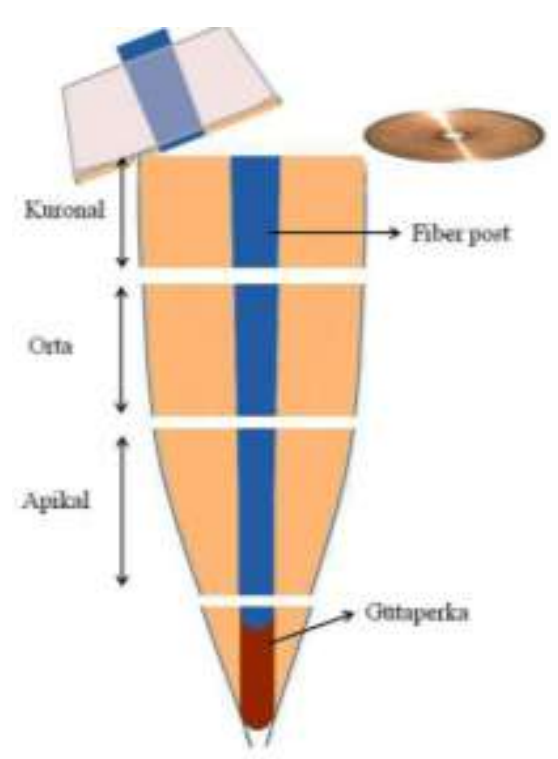

Şekil 1. Mikrosızıntı ölçümlemesi için örneklerin post/dentin kesitlerinin $3 \mathrm{~mm}$ yüksekliğinde elde edilmesi

\section{Mikrosızıntı değerlendirmesi}

Boya penetrasyonunun değerlendirilmesi için her bir kesitin kuronal yüzeyi stereo mikroskop (Olympus SZ61; Olympus Optical Co., Tokyo, Japonya) lensine bakacak şekilde yerleştirildikten sonra $\mathrm{x} 12$ büyütmede görüntülendi ve elde edilen görüntüler stereo mikroskoba bağlı bilgisayara aktarılarak TIFF formatında kaydedildi. Boya penetrasyonu, stereo mikroskoba bağlı görüntü analizörü ve alan ölçme yazılımı yardımıyla (Olympus stream image analysis

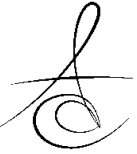


Atatürk Üniv. Diş Hek. Fak. Derg.

J Dent Fac Atatürk Uni

Cilt:24, Sayı:1, Yıl: 2014, Sayfa: 50-57
ERDEMİR, SANCAKLI, ÖZEL, YILDIZ software) her bir görüntü için metilen mavisinin penetre olduğu dentin dokusu alanının $\left(\mathrm{mm}^{2}\right)$ ölçümünün toplam dentin dokusu alanının ölçümüne $\left(\mathrm{mm}^{2}\right)$ oranlanması ile kantitatif olarak değerlendirildi (Şekil 2). ${ }^{25}$

\section{Istatistiksel analiz}

Elde edilen veriler SPSS 17.0 programı (SPSS, Chicago, IL, ABD) kullanılarak Kruskal-Wallis ve MannWhitney $U$ testleri ile $p<0.05$ anlamlılık düzeyinde istatistiksel olarak değerlendirildi.

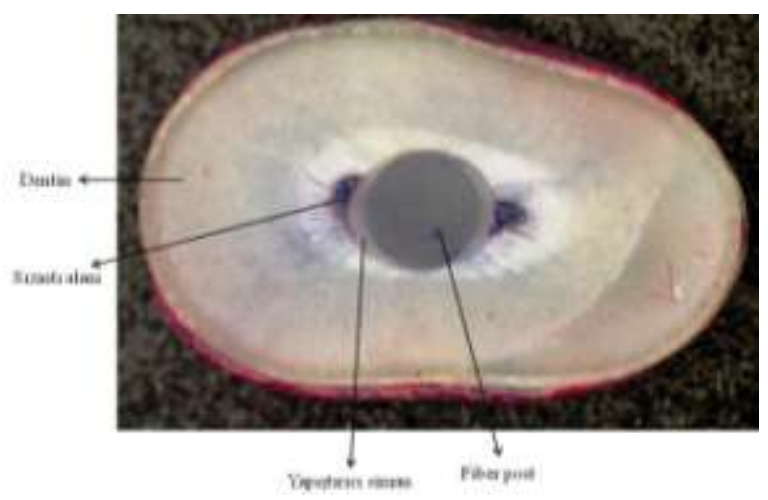

Şekil 2. Boya penetrasyonu olmuş kök kesitinin görüntüsü (x12) ve metilen mavisinin penetre olduğu dentin dokusunun görüntü analizörü yardımıyla ölçümlenmesi $\left(\mathrm{mm}^{2}\right)$.

\section{BULGULAR}

Farklı siman grupları (Panavia F 2.0; RelyX Unicem; Maxcem) ve farklı post tiplerine (Karbon fiber; Cam fiber) göre kök kesitinin her üç bölgesindeki (Kuronal, orta, apikal) mikrosızıntı oranı ortalama değerleri ve standart sapmaları Tablo 2'de gösterilmiştir. Kruskal-Wallis test sonucuna göre, post tipine bakılmaksızın her üç kök kesitinde de Maxcem diğer siman gruplarına göre istatistiksel olarak en yüksek mikrosızıntı oranı değerlerini göstermiştir $(p<0.05)$. Karbon fiber post gruplarında Panavia F 2.0 ve RelyX Unicem adeziv simanlar arasında hem kuronal, hem orta, hem de apikal kök kesitilerinde mikrosızıntı değerleri açısından anlamlı bir farklılık gözlenmezken ( $p>0.05)$, cam fiber post gruplarında Panavia F 2.0 her üç kök kesitinde istatistiksel olarak diğer adeziv simanlara oranla daha az mikrosızıntı oranı göstermiştir ( $p<0.05$; Tablo 2). Post tipleri kıyaslandığında, yapıştırıcı siman tipine bakılmaksızın bütün kök kesitlerinde karbon fiber postlar, cam fiber postlara göre anlamlı olarak daha yüksek mikrosızıntı oranları göstermiştir ( $p<0.05$; Mann-Whitney U test). Aynı adeziv siman ile simante edilen ayn fiber post sisteminin, farklı kök kesitlerindeki (Kuronal, orta, apikal) mikrosızıntı değerleri karşılaştırıldığında tüm kök kesitlerinde istatistiksel olarak anlamlı farklılıklar gözlenmiştir $(p<0.001)$. Kesitler arasında en yüksek sızıntı gösteren kesitten en düşük sızıntı gösteren kesite doğru sıralama yapılacak olursa kuronal< orta<apikal şeklinde sıralanmaktadır $(p<0.001)$.

Tablo 2. Farklı yapıştıııcı simanlar ile simante edilen farklı post tiplerinin kök kesitlerindeki ortalama sızıntı $\left(\mathrm{mm}^{2}\right)$ ve standart sapma (SD) değerleri.

\begin{tabular}{|c|c|c|c|c|}
\hline $\begin{array}{c}\text { Kök } \\
\text { kesiti }\end{array}$ & Post tipi & $\begin{array}{c}\text { Yapıştırıcı } \\
\text { siman }\end{array}$ & Ortalama & SD \\
\hline \multirow[t]{6}{*}{ Kuronal } & \multirow[t]{3}{*}{$\begin{array}{l}\text { Karbon } \\
\text { fiber }\end{array}$} & Panavia F2.0 & $0,011^{a, 1}$ & 0,010 \\
\hline & & RelyX Unicem & $0,013^{a, 2}$ & 0,051 \\
\hline & & Maxcem & $0,049^{\mathbf{b}, \mathbf{3}}$ & 0,019 \\
\hline & \multirow[t]{3}{*}{ Cam fiber } & Panavia F2.0 & $0,007^{a, 4}$ & 0,003 \\
\hline & & RelyX Unicem & $0,013^{b, 5}$ & 0,003 \\
\hline & & Maxcem & $0,029^{c, 6}$ & 0,003 \\
\hline \multirow[t]{6}{*}{ Orta } & \multirow{3}{*}{$\begin{array}{c}\text { Karbon } \\
\text { fiber }\end{array}$} & Panavia F2.0 & $0,004^{a, 1}$ & 0,003 \\
\hline & & RelyX Unicem & $0,005^{a, 2}$ & 0,002 \\
\hline & & Maxcem & $0,016^{\mathbf{b}, 3}$ & 0,004 \\
\hline & \multirow[t]{3}{*}{ Cam fiber } & Panavia F2.0 & $0,001^{a, 4}$ & 0,001 \\
\hline & & RelyX Unicem & $0,005^{b, 5}$ & 0,002 \\
\hline & & Maxcem & $0,021^{c, 6}$ & 0,004 \\
\hline \multirow[t]{6}{*}{ Apikal } & \multirow{3}{*}{$\begin{array}{l}\text { Karbon } \\
\text { fiber }\end{array}$} & Panavia F2.0 & $0,001^{\mathbf{a}, \mathbf{1}}$ & 0,003 \\
\hline & & RelyX Unicem & $0,001^{a, 2}$ & 0,002 \\
\hline & & Maxcem & $0,007^{b, 3}$ & 0,004 \\
\hline & \multirow[t]{3}{*}{ Cam fiber } & Panavia F2.0 & $0,0002^{a, 4}$ & 0,0006 \\
\hline & & RelyX Unicem & $0,0009^{b, 5}$ & 0,001 \\
\hline & & Maxcem & $0,007^{c, 6}$ & 0,006 \\
\hline \multicolumn{5}{|c|}{$\begin{array}{l}\text { Her bir kök kesitinde aynı sütunda farklı küçük harflerle } \\
\text { gösterilen değerler istatistiksel olarak farklıdır }(p<0.05) \text {. } \\
\text { Farklı kesit bölgelerinde aynı sütunda aynı fiber post sistemine } \\
\text { ait aynı yapıştırma siman gruplarında aynı rakamlarla } \\
\text { gösterilen değerler istatistiksel olarak farklıdır }(p<0.05)\end{array}$} \\
\hline
\end{tabular}

\section{TARTIŞMA}

Çalışmadan elde edilen mikrosızıntı oranları değerlendirildiğinde farklı tipteki postların simantasyonunda kullanılan yapıştırıcı siman türleri değişik mikrosızıntı oran değerleri sergilemiştir. Bu nedenle, "kullanılan farklı yapıdaki yapıştırıcı simanlar ile simante edilen farklı post tiplerinin mikrosızıntısının benzer olacağı yönündedir" hipotezi desteklenmemiştir.

Kompozit bir reçine materyali ile kor kısmının yapıldığı karbon fiber postlar yapıştırıcı siman türüne bakılmaksızın, cam fiber postlara oranla daha yüksek mikrosızıntı oranları sergilemiştir. Çalışmada kullanılan pre-fabrike karbon fiber postların yüzeyleri silan ile kaplanmış olarak üretilirken, cam fiber postların yüzeyleri mikroporöz yapıdadır (Üretici firmaların ürün

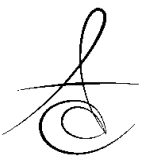


Atatürk Üniv. Diş Hek. Fak. Derg.

J Dent Fac Atatürk Uni

Cilt:24, Sayı:1, Yıl: 2014, Sayfa: 50-57
ERDEMİR, SANCAKLI, ÖZEL, YILDIZ profiline göre). Yüzeyleri daha pürüzlü olan, artmış yüzey alanına sahip cam fiber postların adeziv simanlar ile daha iyi mikromekanik bağlantılar sağlamasının daha az mikrosızıntıya neden olduğunu düşünmekteyiz. Ayrıca post tipleri göz önüne alındığında, karbon fiber postların cam fiber postlara göre ışık iletiminin olmaması, ${ }^{2,28}$ bu post tipinde kökün her üç kesitinde de adeziv simanın yeterince polimerize olamayarak özellikle adeziv siman-post ara yüzeyinde daha zayıf bağlantı oluşturarak mikrosızıntının daha fazla olmasına neden olduğu kanısındayız. Bu bulgumuzu destekler şekilde, Yoldas ve Alacam, ${ }^{29}$ kök kanallarını taklit eden düzenek kullanarak yaptıkları çalışmalarında ışık ileten postlar kullanıldığında kompozit mateyallerin mikrosertliklerinin daha fazla olduğunu bildirmişlerdir.

Çalışmada kullanılan adeziv yapıştırma simanları karşılaştırıldığında, post tipine bakılmaksızın Maxcem grubunda her üç kök kesitinde de diğer siman gruplarına oranla anlamlı oranda daha yüksek mikrosızıntı değerleri gözlenmiştir. Karbon fiber postların Panavia F 2.0 ve RelyX Unicem simanlar ile simante edildiği gruplarda her üç kök kesitinde de anlamlı farklılıklar gözlenmezken, cam fiber postların Panavia $\mathrm{F}$ 2.0 ile simante edildiği gruplar, diğer siman gruplarına oranla istatistiksel olarak daha az mikrosızıntı oranları sergilemiştir. Panavia F 2.0, fosfat bazlı fonksiyonel monomer 10-MDP (10-methacryloyloxydecyl dihydrogen phosphate) içermektedir. Bu molekül hibrit tabaka içinde kollajen etrafında kalan hidroksiapatit ile etkileşime girerek ${ }^{30}$ suda çözünürlüğü az ve daha stabil bir bağ olan MDP-kalsiyum tuzları oluşturur. ${ }^{31}$ Oluşan bu stabil ve çözünürlüğü az olan yapının daha iyi bağlantı sergileyerek daha az mikrosızıntı oranları sergilemiş olabileceğini düşünmekteyiz. Self-adeziv simanlar multifonksiyonel fosforik asit metakrilatları içerirler ve diş dokularını benzer bir mekanizmayla demineralize ederken aynı anda demineralize dokuya infiltre olarak hem hidroksiapatit ile kimyasal reaksiyon oluştururlar hem de mikromekanik retansiyon sağlarlar. $^{32}$ RelyX Unicem simanı, Maxcem simandan farklı olarak fosforik asit metakrilatların nötralizasyon reaksiyonları esnasında su açığa çıkartarak nem toleransı sağlar ve oluşan bu nem simanın başlangıçtaki hidrofilik özelliğine katkı sağlayarak daha iyi bağlanma performansı $^{32,33}$ ve sonuç olarak daha az sızıntı değerleri göstermesine yol açmış olabilir.
Adeziv reçine simanların örtüleme kapasitesi, yüksek C-faktörü, restoratif materyalin boyutsal değişimi (örn; polimerizasyon büzülmesi) ve adeziv reçinenin bağlanma kapasitesi gibi birçok faktörden etkilenebilmektedir. ${ }^{22}$ Bağlanan yüzeylerin bağlanmayan yüzeylere oranı olarak tanımlanan C-faktörünün, ${ }^{26}$ post restorasyonlarında 200'ün üzerinde olabileceği ve bu yüksek C-faktör değerinin polimerizasyon streslerini artırarak, yapıştırıcı simanın dentinden ayrılmasına ve bağlanmanın zayıflamasına neden olabileceği bildirilmiştir. ${ }^{27}$ Çalışmamızda tüm kök kesitlerinde gözlenen sızıntı değerlerinin, yüksek C-faktörü nedeniyle adeziv siman-dentin arası bağlanmanın zayıflaması nedeniyle oluşmuş olabileceğini düşünmekteyiz.

Erkut ve ark ${ }^{25}$ geniş hazırlanmış kök kanallarına 4 farklı fiber post tipi uygulayarak boyanan yüzeylerin boyanmayan yüzeylere oranlaması yapılarak mikrosızıntılarını değerlendirdikleri çalışmalarında, çalışmamızda elde edilen mikrosızıntı değerlerine oranla daha fazla değerler elde etmişlerdir. Bunun nedeninin, çalışmamızda seçilen FGK post tipine uygun kanal hazırlama drilinin kullanılmasının post ile hazırlanan kök kanal dentini arasında daha az bir alanın kalmasına yol açarak adeziv simanın hacimsel büzülmesinin, daha geniş hazırlanan bir kök kanalına oranla daha az olmasından kaynaklandığını düşünmekteyiz. Mikrosızıntı ölçümünün kantitatif olarak değerlendirildiği diğer bir çalışmada ise çalışmamızdan farklı olarak araştırmacılar elli bin siklus yük uygulaması sonrasında farklı post tiplerinin mikrosızıntılarını değerlendirmişlerdir. ${ }^{20}$ Çalışmada post sistemleri kök kanalına total-etching dual-cure adeziv bir siman kullanılarak simante edilmiş ve sonuçta metal döküm postların en yüksek mikrosızıntı değerleri gösterdiği, bunun yanında yük uygulaması altında prefabrike metal post ve fiber post tipleri arasında mikrosızıntı değerleri açısından fark olmadığı bildirilmiştir. Korların kompozit ile yapıldığı post gruplarına oranla metal döküm postlarda görülen yüksek sızıntı değerlerinin post ile dentin arasındaki bağlanmanın daha zayıf olması nedeniyle oluşmuş olabileceği çalışmada belirtilmiştir. ${ }^{20}$ Çalışmamızda tüm kor yapıları aynı bağlayıc ajan ve kompozit materyali kullanılarak yapılmış ve böylece kor yapının dentin yüzeyleri ile bağlantıları arasında oluşabilecek farklılıklar elimine edilmeye çalışılmıştır.

Mikrosızıntı testleri, adeziv sistemlerin örtüleme kapasitesinin değerlendirilmesinde sıklıkla kullanılan ve 
oldukça faydalı test yöntemleridir. Farklı mikrosızıntı test yöntemleri kullanılmasına karşın, restore edilmiş dişlerin boya penetrasyonu sonrası kesitlerinin elde edilerek mikrosızıntılarının değerlendirilmesi yöntemi sıklıkla kullanılan yöntemdir. ${ }^{20,22,25}$ Çalışmamızda boya penetrasyonu sonrasında diş köklerinden üç kesit (kuronal, orta, apikal) alınarak stereo mikroskop altında, görüntü analizörü yardımıyla boyanan yüzey alanlarının $\left(\mathrm{mm}^{2}\right)$ boyanmayan yüzey alanlarına $\left(\mathrm{mm}^{2}\right)$ oranlaması yapılarak geleneksel subjektif skorlama yöntemine göre kantitatif değerler elde edilerek yapılmıştır. Böylece numunelerin mikrosızıntılarının değerlendirilmesinde skorlama ile ilgili farklı değerlendiriciler arasında oluşabilecek hatalar elimine edilmiştir. ${ }^{22}$.

Crim ve Garcia-Godoy ${ }^{34}$ boya penetrasyonunun 100 ile 1500 arasında Isısal dönüşüm işlemine tabi tutulmasının mikrosızıntının değerlendirilmesi açısından bir farklılık yaratmayacağını bildirmişlerdir. Bu nedenle, çalışmamızda, hazırlanan tüm örnekler boya penetrasyonu öncesinde $2500 \mathrm{kez}\left(5^{\circ} \mathrm{C}-55^{\circ} \mathrm{C}\right)$ ISIsal dönüşüm işlemine tabi tutuldu. Mikrosızıntı çalışmalarında kullanılan örnekler için ısısal dönüşüm işleminin yanı sıra mekanik yük uygulaması yapılmasının daha doğru değerler elde etmek açısından uygun olacağı bildirilmektedir. ${ }^{22}$ Ancak, çalışmamızda örnekler üzerine mekanik yük uygulaması yapılmamış olup bu uygulamanın yapılmış olmasının elde edilen mikrosızıntı değerleri üzerine etki edebileceğini bunun da çalışmamızın en önemli kısıtlamalarından birini oluşturduğunu düşünmekteyiz.

\section{SONUÇ}

Çalışmamızın sınırları içinde:

1. Adeziv siman türüne bakılmaksızın karbon fiber postlar cam fiber postlara göre her üç kök kesitinde de daha fazla mikrosızıntı göstermiştir,

2. Self-etch adeziv sistem ile birlikte kullanılan dual-cure adeziv siman, en az sızdırmazlık özelliğine sahip siman olarak bulunmuştur,

3. Self-adeziv siman sistemlerinden Maxcem her iki post tipinde de en fazla mikrosızıntı tespit edilen grup olmuştur,

4. Her üç kök kesitinde de Panavia F ile simante edilen cam fiber postlar en az mikrosızıntı değerleri göstermiştir.

\section{KAYNAKLAR}

1. Sadek FT, Monticelli F, Goracci C, Tay FR, Cardoso $P E$, Ferrari $M$. Bond strength performance of different resin composites used as core materials around fiber posts. Dent Mater 2007;23:95-9.

2. Erdemir U, Mumcu E, Topcu FT, Yildiz E, Yamanel K, Akyol M. Micro push-out bond strengths of 2 fiber post types luted using different adhesive strategies. Oral Surg Oral Med Oral Pathol Oral Radiol Endod 2010;110:534-44.

3. Torbjörner A, Karlsson S, Odman PA. Survival rate and failure characteristics for two post designs. J Prosthet Dent 1995;73:439-44.

4. Kececi AD, Ureyen Kaya B, Adanir N. Micro pushout bond strengths of four fiber-reinforced composite post systems and 2 luting materials. Oral Surg Oral Med Oral Pathol Oral Radiol Endod 2008;105:121-8.

5. Cheung W. A review of the management of endodontically treated teeth. Post, core and the final restoration. J Am Dent Assoc 2005;136:6119.

6. Wang VJ, Chen YM, Yip KH, Smales RJ, Meng QF, Chen L. Effect of two fiber post types and two luting cement systems on regional post retention using the push-out test. Dent Mater 2008;24:3727.

7. Duret B, Reynaud M, Buret F. A new concept of corono-radicular reconstruction, the Composipost (2). Chir Dent Fr 1990;60:69-77.

8. Akgungor G, Akkayan B. Influence of dentin bonding agents and polymerization modes on the bond strength between translucent fiber posts and three dentin regions within a post space. J Prosthet Dent 2006;95:368-78.

9. Asmussen E, Peutzfeldt A, Heitmann T. Stiffness, elastic limit, and strength of newer types of endodontic posts. J Dent 1999;27: 275-8.

10. Ferrari M, Vichi A, Mannocci F, Mason PN. Retrospective study of the clinical performance of fiber posts. Am J Dent 2000;13: 9B-13B.

11. Bateman G, Ricketts DNJ, Saunders WP. Fibrebased post systems: a review. $\mathrm{Br}$ Dent J 2003;195:43-8. 
12. Roberts HW, Leonard DL, Vandewalle KS, Cohen $M E$, Charlton DG. The effect of a translucent post on resin composite depth of cure. Dent Mater 2004;20:617-22.

13. Mazzoni A, Marchesi G, Cadenaro M, Mazzotti G, Di Lenarda R, Ferrari M, Breschi L. Push-out stress for fibre posts luted using different adhesive strategies. Eur J Oral Sci 2009;117:447-53.

14. Nakajima M, Kanemura N, Pereira PN, Tagami J, Pashley DH. Comparative microtensile bond strength and SEM analysis of bonding to wet and dry dentin. Am J Dent 2000;13:324-8.

15. Van Meerbeek B, De Munck J, Yoshida $Y$, Inoue $S$, Vargas $M$, Vijay $P$, Van Landuyt $K$, Lambrechts $P$, Vanherle G. Buonocore memorial lecture. Adhesion to enamel and dentin: current status and future challenges. Oper Dent 2003;28:215-35.

16. Radovic I, Monticelli F, Goracci C, Vulicevic ZR, Ferrari M. Self-adhesive resin cements: a literature review. J Adhes Dent 2008;10:251-8.

17. Akkayan B, Gulmez $T$. Resistance to fracture of endodontically treated teeth restored with different post systems. J Prosthet Dent 2002;87:431-7.

18. Costa RG, De Morais EC, Campos EA, Michel MD, Gonzaga CC, Correr GM. Customized fiber glass posts. Fatigue and fracture resistance. Am J Dent 2012;25:35-8.

19. Saunders WP, Saunders EM. Coronal leakage as a cause of failure in root-canal therapy: a review. Endod Dent Traumatol 1994;10:105-8.

20. Jung SH, Min KS, Chang HS, Park SD, Kwon SN, Bae JM. Microleakage and fracture patterns of teeth restored with different posts under dynamic loading. J Prosthet Dent 2007;98:270-6.

21. Usumez A, Cobankara FK, Ozturk N, Eskitascioglu G, Belli S. Microleakage of endodontically treated teeth with different dowel systems. J Prosthet Dent 2004;92:163-9.

22. Korasli D, Ziraman F, Ozyurt P, Cehreli SB. Microleakage of self-etch primer/adhesives in endodontically treated teeth. J Am Dent Assoc 2007;138:634-40.

23. Wu MK, Wesselink PR. Endodontic leakage studies reconsidered. Part I. Methodology, application and relevance. Int Endod J 1993;26:37-43.

24. Mannocci F, Ferrari M, Watson TF. Microleakage of endodontically treated teeth restored with fiber posts and composite cores after cyclic loading: a confocal microscopic study. J Prosthet Dent 2001;85:284-91.

25. Erkut S, Gulsahi K, Caglar A, Imirzalioglu $P$, Karbhari VM, Ozmen I. Microleakage in overflared root canals restored with different fiber reinforced dowels. Oper Dent 2008;33:96-105.

26. Davidson $\mathrm{CL}$, de Gee AJ, Feilzer A. The competition between the composite-dentin bond strength and the polymerization contraction stres. J Dent Res 1984;63:1396-9.

27. Bouillaguet S, Troesch S, Wataha JC, Krejci I, Meyer JM, Pashley DH. Microtensile bond strength between adhesive cements and root canal dentin. Dent Mater 2003;19 199-205.

28. Pest LB, Cavalli G, Bertani P, Gagliani M. Adhesive post-endodontic restorations with fiber posts: push-out tests and SEM observations. Dent Mater 2002; 18: 596-602.

29. Yoldas O, Alaçam T. Microhardness of composites in simulated root canals cured with light transmitting posts and glass-fiber reinforced composite posts. J Endod 2005;31:104-6.

30. Fukegawa D, Hayakawa S, Yoshida Y, Suzuki K, Osaka A, Van Meerbeek B. Chemical interaction of phosphoric acid ester with hydroxyapatite. J Dent Res 2006; 85:941-4.

31. Tay FR, Pashley DH, Suh BI, Carvalho RM, Itthagarun A. Single-step adhesives are permeable membranes. J Dent 2002; 30:371-82.

32. Radovic I, Monticelli F, Goracci C, Vulicevic ZR, Ferrari M. Self-adhesive resin cements: A literature review. J Adhes Dent 2008; 10: 251-8.

33. Bitter K, Meyer-Lueckel H, Priehn K, Kanjuparambil JP, Neumann K, Kielbassa AM. Effects of luting agent and thermocycling on bond strengths to root canal dentine. Int Endod J 2006; 39: 809-18.

34. Crim GA, Garcia-Godoy F. Microleakage: the effect of storage and cyclic duration. J Prosthet Dent 1987;57:574-6.

\section{Yazışma Adresi:}

Doç. Dr. Uğur ERDEMIR

Adres: İstanbul Üniversitesi Dişhekimliği Fakültesi Diş Hastalıkları ve Tedavisi AD, Kat: 4, Millet Cd. Çapa-Fatih/İstanbul

E-posta: uerdemir@istanbul.edu.tr

TIf: 2124142020

Faks: 2125250075 